\title{
A 15-Year Follow-up of AJCC Stage III Malignant Melanoma Patients Treated Postsurgically with Newcastle Disease Virus (NDV) Oncolysate and Determination of Alterations in the CD8 T Cell Repertoire
}

\author{
Franak M. Batliwalla, ${ }^{1}$ Barbara A. Bateman, ${ }^{2}$ Davide Serrano, ${ }^{1}$ \\ Douglas Murray, ${ }^{3}$ Stuart Macphail, ${ }^{1}$ V. C. Maino, \\ John C. Ansel, 2,4 Peter K. Gregersen, ${ }^{1}$ and \\ Cheryl A. Armstrong ${ }^{2,4}$ \\ ${ }^{1}$ North Shore University Hospital-NYU School of Medicine, 350 \\ Community Drive, Manhasset, New York, U.S.A. \\ Departments of ${ }^{2}$ Dermatology, and ${ }^{3}$ Surgery, Emory University School \\ of Medicine, Atlanta, Georgia, U.S.A. \\ ${ }^{4}$ Veterans Affairs Medical Center, Atlanta, Georgia, U.S.A. \\ ${ }^{5}$ Becton Dickinson, Qume Drive, San Jose, California, U.S.A. \\ Accepted October 28, 1998.
}

\begin{abstract}
Background: The development of effective adjuvant therapies for the treatment of high-risk melanoma patients is critical for the prevention of metastatic disease and improvement of patient survival. Active specific immunotherapy has been tested as an adjuvant treatment in numerous clinical trials with overall limited, but occasionally promising, success rates. Newcastle disease virus (NDV) oncolysate has been utilized as an adjunctive immunotherapeutic agent in the postsurgical management of these patients. A phase II study initiated in 1975 using adjuvant vaccine therapy composed of allogeneic and autologous human melanoma cells infected with live NDV (NDV oncolysate) in patients with AJCC stage III melanoma following therapeutic lymph node dissection has shown $>60 \%$ survival rate at 10 years with no adverse effects. Continued long-term analysis of trials with promising early results as well as assessment of immunologic responses generated in these patients may result in improved therapeutic decisions for clinical trials in the future.
\end{abstract}

Materials and Methods: We analyzed the 15-year survival of patients treated postsurgically with NDV oncolysate in the phase II study described above. In an attempt to understand the immunological effects of this treatment, we have also carried out a comprehensive analysis of the peripheral blood $\mathrm{T}$ cell repertoire in these patients.

Results: The overall 15-year survival of this group of patients is $55 \%$. Previous studies have suggested that improved outcome in patients undergoing immunotherapy is correlated with increased numbers of $\mathrm{CD} 8^{+} \mathrm{CD} 57^{+}$cells. In surviving patients, we observed a striking oligoclonality in the $\mathrm{CD}^{+} \mathrm{T}$ cell population in peripheral blood, which reflects clonal expansions in the $\mathrm{CD}^{+} \mathrm{CD} 57^{+}$subset.

Conclusions: The data suggest that adjuvant vaccination with NDV oncolysates is associated with prolonged survival of patients with lymph node-positive malignant melanoma and that $\mathrm{CD}^{+} \mathrm{T}$ cells may be an important component of therapeutic efficacy.

\section{Introduction}

Cutaneous malignant melanoma is responsible for approximately three-fourths of all skin cancer-associated deaths (1). The incidence of melanoma in the Caucasian population has continued to increase at an alarming annual rate of $6 \%(2)$. Whereas the estimated lifetime risk for malignant melanoma in the U.S. was 1 in 1500 in 1935, it is expected to be 1 in 75 by the year 2000 (2). In addition, malignant melanoma rates are increasing faster than any other cancer among men and are second only 
to lung cancer among women (3). Thin primary melanomas (thickness $<0.75 \mathrm{~mm}$ ) are successfully treated with surgical excision with a 5 -year survival rate of $>98 \%$ (4). However, the 5 -year survival rate of patients with thick primary cutaneous melanomas $(>4.0 \mathrm{~mm})$ is $<50 \%$ (4). Patients with nodal metastatic disease have a $36 \%$ survival rate at 5 years, which decreases to only $5 \%$ if distant metastases are present (5).

Treatment options beyond surgery that may prevent recurrent disease are limited for patients with thick primary melanomas or those with melanoma present in regional lymph nodes, although the search for effective adjuvant therapies for the treatment of these high-risk melanoma patients is actively pursued. These attempts have included trials with interferons, specific and nonspecific immunotherapy, adjuvant chemotherapy and chemoimmunotherapy, isolated limb perfusion, adjuvant radiation therapy, adjuvant hormonal therapy, and adjuvant retinoid therapy $(6-13)$. The development of approaches employing active specific immunotherapy with therapeutic melanoma vaccines was prompted by clinical observations, suggesting an important role of the immune system in melanoma (7). Therapeutic vaccines employing purified gangliosides, shed antigens, specific isolated peptides, mechanical or viral melanoma cell lysates, and allogeneic or autologous whole cell preparations have been used as postoperative treatments for prevention and regression of tumor metastases because of the potential ability of the immune system to distinguish tumor cells from normal cells and selectively destroy the tumor $(8-13)$.

Most of these approaches have shown little survival advantage over surgical therapy only and the interpretation of results is complicated by problems with experimental design that are often inherent in small clinical studies (13).

\footnotetext{
Stuart Macphail's current address: Fish and Richardson, 45 Rockefeller Plaza, New York, NY 10111.

Address correspondence and reprint requests to: Dr. Peter K. Gregersen, Department of Medicine, North Shore University Hospital-NYU School of Medicine, 350 Community Drive, Manhasset, NY 11030, U.S.A. Phone: 516-562-1542; Fax: 516-562-1683; E-mail: peterg@nshs.edu or Dr. Cheryl A. Armstrong, Department of Dermatology, Emory University School of Medicine, 5001 Woodruff Memorial Building, Atlanta, GA 30322; Phone: 404-727-1658; Fax: 404727-5217; E-mail: carms01@emory.edu
}

Additionally, little information about the host immunologic response to these therapeutic agents has been obtained. However, several of these approaches have suggested promising results and several randomized phase III trials are in progress (14-16). Recently, high-dose interferon $\alpha-2 b$ (Intron-A; Schering Plough) has been shown in a randomized, controlled trial to have a positive effect on disease-free and overall survival in the postsurgical adjuvant setting for high-risk melanoma, making this agent the current standard of care for these patients (17). These positive results, although limited, have served to trigger a renewed interest in immunotherapeutic approaches as adjuvant therapy for high-risk melanoma patients.

Previous studies by Cassel and Murray and colleagues at Emory University have successfully utilized postsurgical vaccination with a Newcastle disease virus (NDV) oncolysate as adjuvant therapy in the treatment of metastatic melanoma (18-23). The survival of American Joint Committee on Cancer (AJCC) stage III melanoma patients with palpable lymph nodes treated with this NDV oncolysate in a phase II study initiated in 1975 was $>60 \%$ at 10 years (23). This result can be compared to the $6-15 \% 10$-year survival of comparable historical patient populations with palpable lymph node disease (24-26) and the 33\% survival rate at 10 years observed in historical studies in which patients with occult lymph node disease were included $(27,28)$. We now report the 15-year status of 83 malignant melanoma patients enrolled in this phase II study, which consisted of therapeutic removal of palpable, diseased lymph nodes and long-term subcutaneous vaccination with NDV oncolysate. The enhanced survival of this unique patient population undergoing chronic immunization with viral oncolysate prompted us to investigate the immunological effects of this treatment. We have extensively analyzed the $\mathrm{T}$ cell receptor (TCR) repertoire of these patients and have detected significant $\mathrm{T}$ cell oligoclonal expansions, particularly within the CD8 subset. These results suggest that CD8 $T$ cell responses are an important component of therapeutic efficacy. 


\section{Materials and Methods}

Patients

Our study focused on patients enrolled in a phase II study initiated at Emory University in 1975 to test the ability of NDV oncolysate to affect survival in stage III AJCC malignant melanoma patients. Between 1975 and 1979, 32 patients were selected as group I. These patients had a mean age of 39 years and $71 \%$ of the group was male. A second, repeat study was then initiated on a separate group to determine if the survival pattern of group I could be duplicated. Group II consisted of 51 patients (mean age 46 years, $73 \%$ male) selected through 1982. No control group was recruited since this was designed as a phase II study. The specifics of patient selection and demographics have been previously described in detail (23). In summary, all patients in the study had metastatic disease in palpable regional lymph nodes that was confirmed by pathology following therapeutic lymph node dissection. Initial extensive scanning revealed no detectable disease beyond regional lymph nodes.

\section{Preparation and Administration of Viral Oncolysate}

The methods used for the preparation and administration of the NDV oncolysate have been previously described $(23,29)$. Briefly, the lysed products from NDV-infected monolayers of 10 lines of human melanoma cell lines established from melanoma patients were infected with NDV strain 73T. Cell lines were successfully established from only four of the patients in group I who were enrolled to receive NDV oncolysate therapy. The lysed cellular products and live NDV were concentrated 10 -fold and stored at $-70^{\circ} \mathrm{C}$ prior to use $(23)$. Patients received allogeneic oncolysates in rotating combinations (23). Four group I patients received both allogeneic and autologous oncolysate in rotating combinations (23). The oncolysate mixture was given as a 2.5-ml subcutaneous injection and was administered at weekly intervals, gradually extending to a 3-month interval over a period of 5 years (23). At the end of this study period, institutional approval was obtained to continue NDV oncolysate treatment. Currently, 34 of these 83 patients continue to receive NDV oncolysate injections at varying intervals of 3, 4, or 6 months. Only patients who continued to receive oncolysate therapy have been used in the analysis of the $\mathrm{T}$ cell repertoire of peripheral blood lymphocytes described below.

\section{Determination of 15-Year Survival}

Fifteen years after the initiation of therapy in all 83 patients, a complete medical record review was undertaken for all patients in groups I and II of this phase II trial. Those patients lost to follow-up were either contacted personally or a family member was contacted to obtain an interval medical history. For statistical analysis, survival has been determined from initiation of NDV oncolysate therapy following nodal dissection. The survival status of a patient was considered to be "dead of disease" if the patient died as a result of melanoma. Nine patients died from unrelated causes and were free of melanoma at the time of death. These patients have not been included in the statistical determination of survival. This reduces the total number of patients included in the survival analysis to 74 .

\section{Separation of Cells for Immunologic Studies}

Peripheral blood was obtained from melanoma patients who continue to actively participate in the NDV oncolysate immunization protocol. Control samples were obtained from normal, healthy age-matched adult volunteers. No pretreatment blood samples are available for any of the patients enrolled in this study, nor did we have access to peripheral blood samples from untreated stage III melanoma patients who have survived for 15 years. Peripheral blood mononuclear cells (PBMC) were isolated by FicollHypaque density gradient centrifugation for 20 min at $2000 \mathrm{rpm}$ at $200^{\circ} \mathrm{C}$, washed twice, first in Hanks' Balanced Salt solution (Life Technologies, Grand Island, NY) and then in a phosphate-buffered saline (PBS)-1\% BSA solution, and resuspended in PBS-1\% BSA at a concentration of $1 \times 10^{6}$ cells per $100 \mu \mathrm{l}$.

\section{Immunomagnetic Separation of $C D 4^{+}$and $C D 8^{+} T$ Cells and RNA Extraction}

PBMC from NDV oncolysate-treated melanoma patients and age-matched controls were used to positively select $\mathrm{CD}^{+}$and $\mathrm{CD}^{+}{ }^{+} \mathrm{T}$ cells by incubating with immunomagnetic beads (Dynal, Great Neck, NY). PBMC were resuspended at $10 \times 10^{6}$ cells $/ \mathrm{ml}$ and were incubated with prewashed amounts of anti-CD4 or anti-CD8 beads for $30 \mathrm{~min}$ at $4^{\circ} \mathrm{C}$ on a rotating shaker according to the manufacturer's instructions. The cells bound to the beads were used for extraction of total RNA using Tri reagent (Sigma, St. Louis, $\mathrm{MO})$ as recommended by the manufacturer. 


\section{Multiplex CDR3 Length Analysis of TCR V $\beta$ Chains}

A multiplex radioactive polymerase chain reaction (PCR) assay described previously (30) was used to assess length variation of the CDR3 loop in the TCR $\beta$ chain. In brief, total RNA was used for first-strand CDNA synthesis using a TCR $\beta$-chain $C$-region primer $(C \beta$-14:5' CTC AGC TCC ACG TC $\left.3^{\prime}\right)$. An aliquot of cDNA was then used for subsequent TCR $\beta$-specific PCR amplification using a radiolabeled $C \beta$ reverse primer, and upstream $\mathrm{V} \beta$-specific forward primers in multiplex combinations as described previously (31). Six microliters of the amplified products was loaded on a standard $6 \%$ acrylamide sequencing gel. Bands were visualized after overnight exposure to Kodak AR film or analyzed using a Phosphorimmager (Molecular Dynamics, Sunnyvale, CA).

\section{Monoclonal Antibodies and Reagents for Flow Cytometry}

Monoclonal antibodies to CD57, CD3, CD8; rat anti-mouse IgGl, rat anti-mouse $\operatorname{IgG} 2 \mathrm{a}+\mathrm{b}$, streptavidin PerCP, anti-human interferon gamma (IFN- $\gamma$ ), TNF $\alpha$, and IL-2 were purchased from Becton Dickinson (San Jose, CA). Anti-CD8 IgG2a-biotin was purchased from Leinco Technologies, Inc. (St. Louis, MO), and TIA-1 was purchased from Coulter Corp. Monoclonal antibodies (MAb) to Va2 (Fl.2), V $\beta 3.1$ (8F10), V $\beta$ 5.1 (LC4), V $\beta 8$ (16G8), V $\beta 12$ (S5I1), Val2.1 (6D6), and $V \beta$ 13.1/13.3 (BAMI3) were generously donated by $\mathrm{T}$ Cell Sciences, Inc. (Cambridge, MA); anti-V $\beta$ 7.1, by Dr. Margaret Callan (32); anti-V $\beta$ 13.2, by Brian Kotzin (33); anti-V $\beta$ 17 , by Steven Friedman (34); and anti-V $\beta 11$ and anti-Va24, by Antonio Lanzavecchia (35). Monoclonal antibodies to other TCR V $\beta$ segments used for this study were obtained from the TCR monoclonal antibody workshop (36).

\section{Immunofluorescent Staining and FACS Analysis}

We were able to triple stain simultaneously for $\mathrm{CD} 57, \mathrm{CD} 8$, and various $\mathrm{V} \alpha$ and $\mathrm{V} \beta$ segments of the TCR by using an isotype-specific matched protocol of first and second stage reagents that we have previously described (37). Briefly, $50 \mu \mathrm{l}$ $\left(0.5 \times 10^{6}\right.$ cells $)$ of PBMC suspended in PBS-1\% BSA was incubated for $30 \mathrm{~min}$ on ice in the dark with MAb to a single $\mathrm{V}$ segment and either CD8 (IgG1) or CD8 (IgG2a) coupled to biotin, depending on the isotype of the anti- $\mathrm{V}$ segment antibody. Cells were subsequently washed and a second incubation was undertaken with matched second stage reagents and CD57 (IgM) FITC under the same conditions as above. Streptavidin PerCP was also added to those samples initially stained with CD8-biotin. At the end of the incubation times the cells were washed, fixed, and analyzed for the expression of all three markers on a FACScan (Becton Dickinson) flow cytometer and the fluorescence compensation was adjusted using standard methods. Data analysis was done using Cell Quest software (Becton Dickinson Immunocytometry systems). Backgating on the $\mathrm{CD} 8^{+}, \mathrm{CD} 57^{+} \mathrm{T}$ cells enabled the calculation of the percentages of $\mathrm{CD} 3$ and each $\mathrm{V}$ segment in this subpopulation.

\section{Intracellular Staining for Cytokines}

Whole blood was diluted 1:1 with RPMI and incubated with Brefeldin A (10 $\mu \mathrm{g} / \mathrm{ml})$ (Sigma) in the absence or presence of PMA (10 ng) (Calbiochem) and ionomycin ( $1 \mu \mathrm{M})$ (Sigma) for 4 $\mathrm{hr}$ at $37^{\circ} \mathrm{C}$. At the end of the incubation period, $100 \mu$ laliquots were surface stained with anti$\mathrm{CD} 8$ and the relevant anti- $\mathrm{V} \beta$ monoclonal antibodies, washed, and fixed. The red blood cells (RBCs) were lysed with FACS lysing solution (Becton Dickinson), washed, and permeabilized with Permeafix (Ortho Diagnostics), and stained intracellularly with anti-human INF- $\gamma$, tumor necrosis factor $\alpha$ (TNF- $\alpha$ ), or interleukin-2 (IL2). Upon completion of staining, the samples were fixed with $1 \%$ paraformaldehyde-PBS and analyzed for the expression of all three markers on a FACScan (Becton Dickinson). Electronic gates were set on the lymphocyte population based on their forward and side light scatter, and cytokine expression by the $\mathrm{CD} 8^{+} \mathrm{V} \beta^{+}$cells was compared in resting and stimulated samples.

\section{Results}

\section{Long-term Survival of Patients Treated with NDV} Oncolysate

The survival of AJCC stage III malignant melanoma patients 15 years after initiation of therapy with NDV oncolysate remains encouraging. The survival of patients in group I at 15 years is $59 \%$ (18/30). One patient is currently experiencing recurrent metastatic melanoma (patient 40) and one patient has prostate cancer. The patients in group II have a 15 -year survival of $53 \%(23 / 44)$. One patient in this group is currently being treated for breast cancer. Of the four patients 


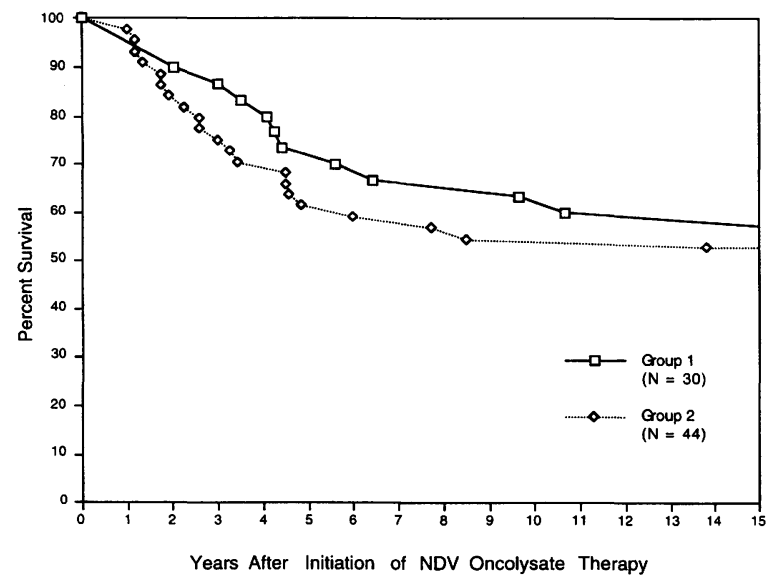

Fig. 1. Kaplan-Meier curve demonstrating the 15-year survival of AJCC stage III malignant melanoma patients treated postsurgically with NDV oncolysate.

that received oncolysate made from both autologous and allogenic melanoma cells, $50 \%$ are alive after more than 15 years (2/4). The survival of these patients is shown as a Kaplan-Meier survival curve (Fig. 1). Over this extended time period, no treated patients developed neurologic disorders as determined by medical history or exhibited any type of adverse reaction to the injected NDV oncolysate, according to clinical observation.

The survival statistics were also analyzed in terms of the number of positive lymph nodes at therapeutic lymph node dissection as determined histologically (Table 1). Group I had 15 patients with 1 positive lymph node. Of these, 10 (67\%) are still surviving. Group II had 20 patients with 1 positive lymph node. Of these, $9(45 \%)$ are still surviving. Of those patients with 2-4 positive lymph nodes, group I had 13 patients with 8 $(62 \%)$ still surviving and group II had 14 patients with $8(57 \%)$ still surviving. Group I had 2 patients with 5 or more positive lymph nodes. Neither $(0 \%)$ of these patients are surviving. Group II had 10 patients with 5 or more positive lymph nodes. Six $(60 \%)$ of these patients are survivors. Thus, there is no particular correlation between 15 -year survival and the number of lymph nodes exhibiting histologic evidence of metastatic melanoma prior to initiation of adjuvant NDV oncolysate therapy.

\section{Clonal Expansions of $C D 8^{+} T$ Cells in Treated Melanoma Patients}

A multiplex reverse transcriptase PCR assay for CDR3 length was used to detect clonality in the peripheral blood TCR in melanoma patients treated with NDV oncolysate and in age-matched controls. Restriction in CDR3 length was detected as a dominant band within the cluster of bands derived from each TCR V $\beta$ segment family. A band is defined as dominant when the counts in the band are $>50 \%$ of the total counts within the particular TCR V $\beta$ family. We have previously established that this criterion is a conservative measure of underlying oligoclonality (38). Figure 2 shows an example of such an analysis in one individual. Note that there are numerous dominant bands in the CD8 subset (lanes A-L, Fig. 2A), in contrast to the apparent gaussian distribution of TCR $V \beta$ length seen in the $\mathrm{CD} 4$ subset (lanes A-L, Fig. 2B).

Figure 3 summarizes the results of oligoclonal expansions detected in 27 melanoma patients treated with NDV oncolysate and 23 agematched normal individuals. The mean number

Table 1. 15-Year survival of AJCC stage III malignant melanoma patients treated postsurgically with Newcastle disease virus oncolysate

\begin{tabular}{|c|c|c|c|c|c|}
\hline \multirow[b]{2}{*}{ Group } & \multirow{2}{*}{$\begin{array}{l}\text { No. of } \\
\text { Patients }\end{array}$} & \multicolumn{3}{|c|}{$\begin{array}{c}\text { Correlation of Survival and No. of Positive Lymph } \\
\text { Nodes at Time of Therapeutic Lymph } \\
\text { Node Dissection }\end{array}$} & \multirow{2}{*}{$\begin{array}{c}\text { Overall } \\
\text { Survival }\end{array}$} \\
\hline & & 1 Node & 2-4 Nodes & $5+$ Nodes & \\
\hline I & 30 & $10 / 15(67 \%)$ & $8 / 13(62 \%)$ & $0 / 2(0)$ & $18 / 30(59 \%)^{a}$ \\
\hline II & 44 & $9 / 20(45 \%)$ & $8 / 14(57 \%)$ & $6 / 10(60 \%)$ & $23 / 44(53 \%)^{b}$ \\
\hline
\end{tabular}

${ }^{a}$ Includes one patient currently with recurrent metastatic melanoma, and one patient currently with prostate cancer.

${ }^{b}$ Includes one patient currently with breast cancer. 


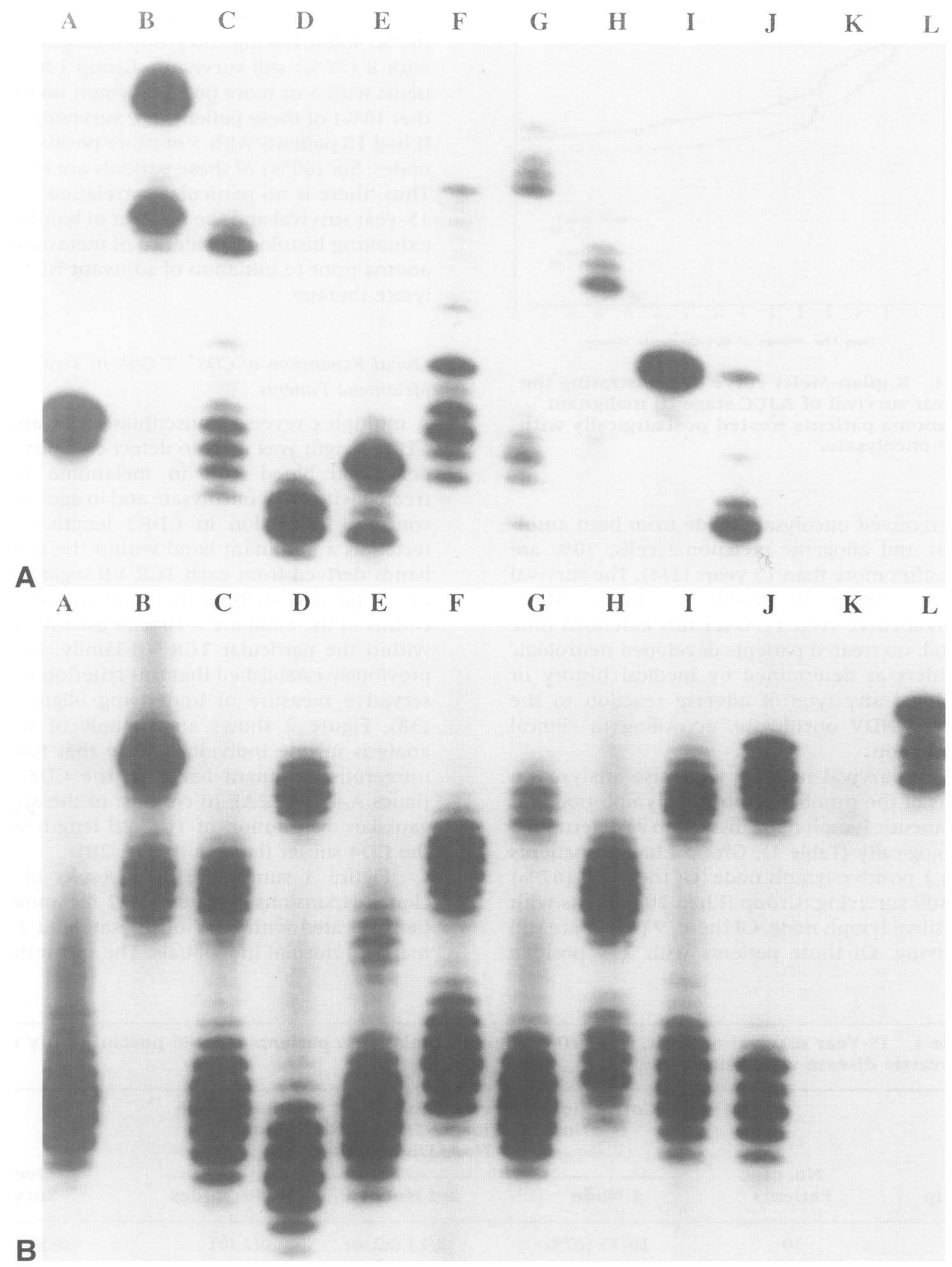

Fig. 2. Representative multiplex PCR analysis of the CDR3 length assay on $\mathrm{CDB}^{+}(\mathrm{A})$ and $\mathrm{CD4}^{+}$(B) $\mathrm{T}$ cell subsets. Lanes A-L correspond to the following sets of TCR V $\beta$ primers from the lower to higher groups of bands: $A: V \beta 1,18,23 ; B: V \beta 2$, 4, 8; $\mathrm{C}: \mathrm{V} \beta$ 3, 13.1; $\mathrm{D}: \mathrm{V} \beta$ 5.2, 5.1; $\mathrm{E}: \mathrm{V} \beta$ 6, 20; F: $\mathrm{V} \beta$ 7, 22; G: V $\beta$ 9, 16; $\mathrm{H}: \mathrm{V} \beta$ 11, 12; I: V $\beta$ 15, 13.2;
$\mathrm{J}: \mathrm{V} \beta$ 14, 17; $\mathrm{K}: \mathrm{V} \boldsymbol{\beta} 10,24 ; \mathrm{L}: \mathrm{V} \boldsymbol{\beta} 2 \mathrm{2}$. Note that there is a dropout of some $V \beta$ families seen in Figure $2 \mathrm{~A}$ and $B$. Note that $V \beta$ 18, 23, 2, 24 are not expressed in this individual (lanes A, B, K). Additionally, there are other $\mathrm{V} \boldsymbol{\beta}$ families that are not detected in the $\mathrm{CD}^{+} \mathrm{T}$ cell subset. This is not uncommon in the setting of an extensively skewed CD8 repertoire. 


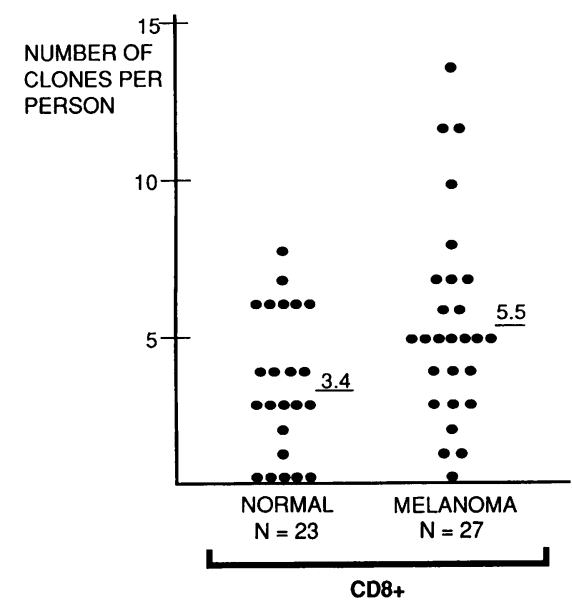

Fig. 3. Melanoma patients immunized with NDV oncolysates demonstrate increased oligoclonality in the CD8 compartment compared with age-matched controls.

of clones detected per person is 3.4 for normal subjects and is 5.5 clones per melanoma patient in the $\mathrm{CD}^{+} \mathrm{T}$ cell compartment $(p<0.03)$. Oligoclonality was also detected in the $\mathrm{CD}^{+} \mathrm{T}$ cell subset as 19 dominant bands in the 21 melanoma individuals analyzed, whereas 7 out of 22 instances of clonality were detected in agematched controls. This difference did not reach statistical significance $(p<0.07)$.

Increased Expression of CD57 in the $C D 8^{+} C D 3^{+} T$ Cell Population of Melanoma Patients Treated with NDV Oncolysate

We have previously shown that CD8 clonality is preferentially detected in the $\mathrm{CD} 28^{-} \mathrm{CD} 57^{+}$subset of CD8 T cells (37). Therefore, 33 melanoma patients treated with NDV oncolysate and 36 age-matched adult volunteers were analyzed for the expression of the CD57 surface marker by flow cytometry. The expression of CD57 was significantly higher on the $\mathrm{CD}^{+} \mathrm{CD}^{+} \mathrm{T}$ cells of melanoma patients than on control cells $(37.2 \%$ vs. $26.2 \%, p<0.03)$.

Clonal Expansion in the $C D 8^{+} C D 57^{+} T$ Cell Subset of Melanoma Patients Treated with Oncolysate

Previous studies performed in our laboratory have established a correlation between oligo-

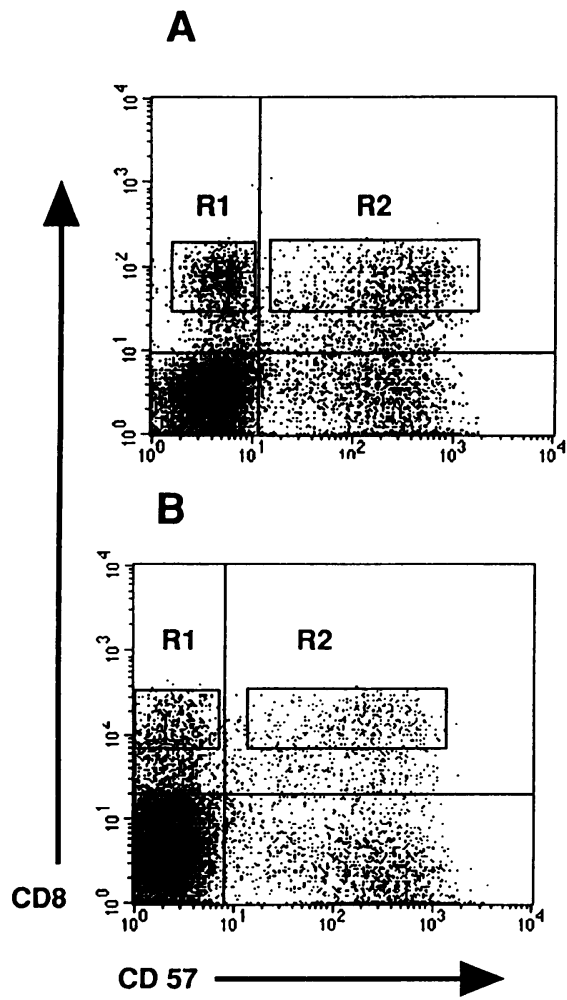

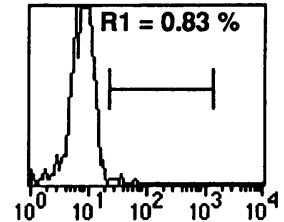

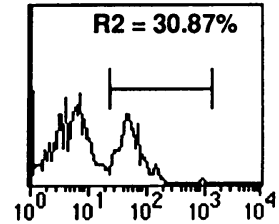

Patient\# 10

VB 16
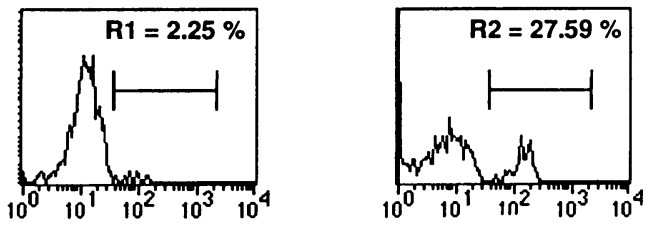

Patient\# 31

Fig. 4. FACS analysis of $\mathrm{CD8}^{+} \mathrm{T}$ cells from two melanoma patients treated with NDV oncolysates. Backgates on the $\mathrm{CD}^{+} \mathrm{CD} 57^{-}(\mathrm{R} 1)$ and $\mathrm{CD} 8^{+} \mathrm{CD} 57^{+}$(R2) $\mathrm{T}$ cell subsets show a marked difference in the frequency of cells carrying the V $\beta 16$ and $V \beta 14$ TCR in these two individuals. 


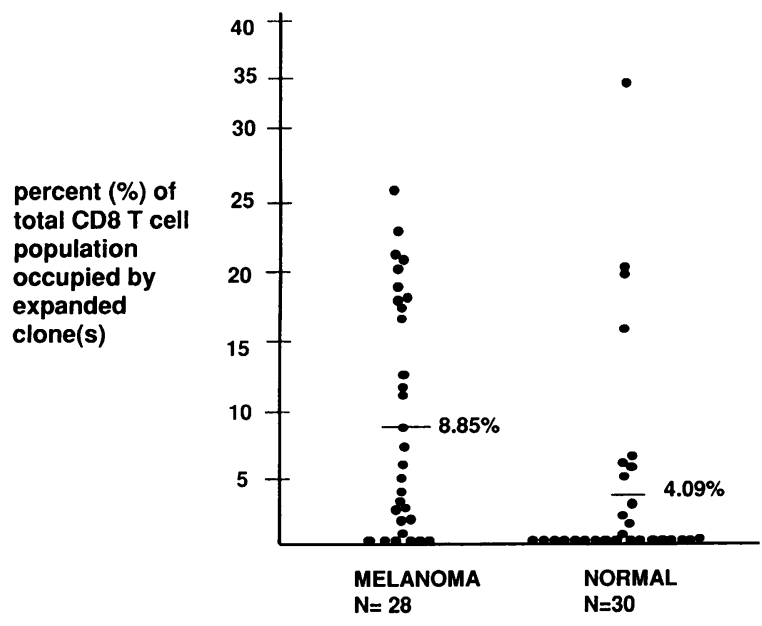

Fig. 5. Oligoclonal expansions in the $\mathrm{CD}_{57}^{+} \mathrm{T}$ cell subset as a percentage of the total $\mathrm{CD8}^{+} \mathrm{T}$ cell population. Results from individuals with one or more expansions of $>10 \%$ within the $\mathrm{CD} 8^{+} \mathrm{CD} 57^{+}$subset detected by FACS analysis are shown.

clonality in the $\mathrm{CD}^{+} \mathrm{T}$ cell population (as determined by the CDR3 length assay) with cellular expansions within the $\mathrm{CD} 28^{-} \mathrm{CD} 57^{+}$subset (as assessed by FACS analysis with $\mathrm{V} \beta$-specific antibodies) (39). In order to demonstrate this correlation in melanoma patients treated chronically with NDV oncolysate, we performed three color flow cytometric studies on these patients. Figure 4 illustrates two examples of such an analysis. Panel A depicts an expansion of TCR V $\beta$ 16 in a study subject (patient 10 ) at $30.87 \%$ in the $\mathrm{CD}^{+} \mathrm{CD}^{+} \mathrm{CD} 57^{+}$subset ( 22 gate), while the expression of $\mathrm{V} \beta 16$ in $\mathrm{CD} 3^{+} \mathrm{CD} 8^{+} \mathrm{CD} 57^{-}$ cells (R1 gate) was only $0.83 \%$. Panel $B$ shows similar patterns of $\mathrm{T}$ cell expansions in another individual for $\mathrm{V} \beta 14$ (patient 31). These expansions correlated with clonality seen by the CDR3 length analysis, and demonstrate the preferential accumulation of the clonally expanded cells within the $\mathrm{CD} 8{ }^{+} \mathrm{CD} 57^{+}$subset.

For the purposes of descriptive analysis, a TCR V segment was considered an "expansion" if it exceeded $10 \%$ in the $\mathrm{CD} 8{ }^{+} \mathrm{CD} 57^{+} \mathrm{T}$ cell subset. Using this criterion, TCR V expansions were detected in the $\mathrm{CD} 8{ }^{+} \mathrm{CD} 57^{+}$subset in 22 out of $28(79 \%)$ melanoma patients treated with NDV oncolysate, compared with only 11 out of $30(37 \%)$ age-matched controls $(p<$ 0.002 ). We also calculated the contribution of the clonally expanded cells to the total $\mathrm{CD}^{+}$ population in melanoma patients and in agematched controls. These data are shown in Figure 5. The mean percent of the CD8 T cell compartment that was occupied by expansions was 4.09 in the control group and 8.85 for the melanoma patients $(p<0.003)$. These frequencies of expansions are likely to be underestimates of the actual frequencies due to the limited range of TCR V segments for which specific antibodies are available.

\section{Functional Potential of the Clonally Expanded $C D 8^{+} C D 57^{+} T$ Cells}

Whole blood was stimulated with phorbol myristate acetate (PMA) and ionomycin to determine the functional capacity of these cells to express cytokines. Figure 6 depicts flow cytometric analysis of activated $V \beta 11$ cells from patient 42. These cells constitute approximately $20 \%$ of the total CD8 population. Backgating on the

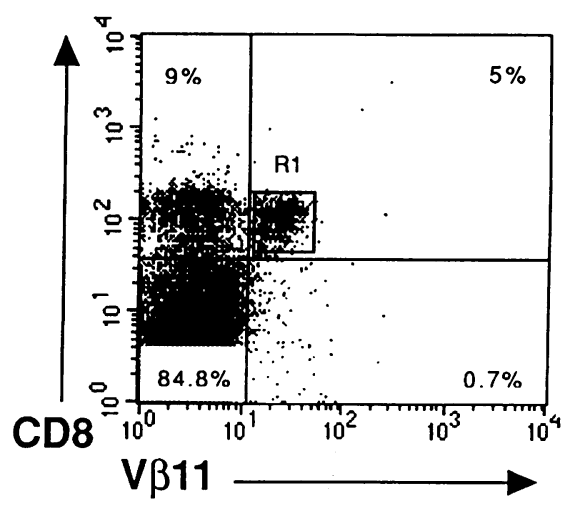

\section{Interferon- $\gamma$}

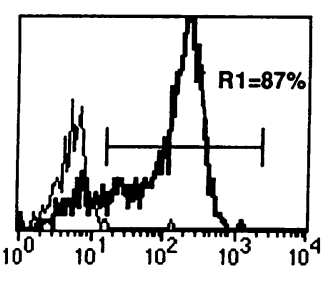

TNF- $\alpha$

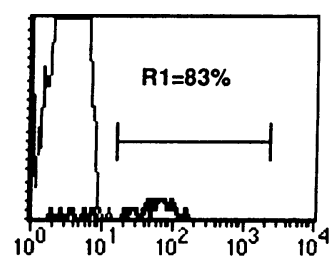

IL-2

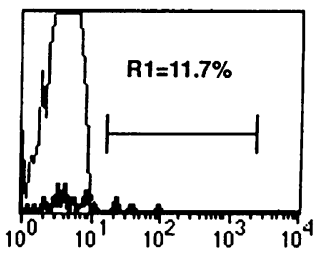

Fig. 6. FACS dot plot and histograms for patient 42. Clonally expanded cells have the potential to produce INF- $\gamma$ and TNF- $\alpha$, but make very little IL-2. The light histogram curves are those of resting cells while the darker histograms represent activated cells. 
$\mathrm{CD} 8^{+} \mathrm{V} \beta 11^{+}$cells shows that $87 \%$ of these clonally expanded $\mathrm{V} \beta 11$ cells produce IFN- $\gamma$ upon stimulation, and $83 \%$ make TNF- $\alpha$; however, they make very little IL-2 either in the resting or activated state. In results not shown, these V $\beta$ 11 expanded cells also express TIA- 1 , an antigen that is expressed by cells that have cytotoxic potential, and cell lines generated from these expanded clones can kill in redirected cytotoxicity assays.

\section{Discussion}

The use of Newcastle disease virus and other virus therapies in the treatment of advanced neoplastic disease dates back several decades $(40,41)$. NDV is a paramyxovirus also known as avian pneumoencephalitis virus. While it is a serious viral disease of birds marked by involvement of the respiratory and nervous systems, humans usually develop only a temporary conjunctivitis if they become infected by direct handling of sick birds. NDV has been evaluated as an anticancer agent because this virus has been shown to have direct toxic effects on tumor cells as well as indirect effects that appear to be mediated through stimulation of the host immune system $(40-43)$. NDV has been utilized alone and in combination with autologous and allogeneic tumor cells to generate viral oncolysates that can be delivered as a vaccine to patients with advanced metastatic disease (18,44-47). Two main strains of NDV have been the focus of most clinically related studies. These are the nonlytic Ulster strain and the lytic NDV $73 \mathrm{~T}$ strain. The latter was developed in 1965 by Cassel and Garrett by passaging NDV 379-S1 through Ehrlich ascites tumor cells in vitro 73 times and in vivo 13 times to eliminate the neurotrophic properties of this strain (44). NDV 73T was found to exhibit limited affinity for nervous tissue when tested in mice, rabbit, guinea pig, Syrian hamster, and Wistar albino rat. The NDV $73 \mathrm{~T}$ strain was used to prepare viral oncolysates in the phase II clinical trial of adjuvant immunotherapy for malignant melanoma described in this study (29).

We have reviewed the clinical outcome and immunologic effects of long-term NDV oncolysate vaccination in the treatment of high-risk AJCC stage III malignant melanoma patients following therapeutic lymph node dissection. The 15-year survival for two groups of patients accrued independently and treated with NDV oncolysate is $59 \%$ for group I and $53 \%$ for group II with an overall survival of $55 \%$. The survival of patients in groups I and II does not differ significantly from each other, indicating the reproducibility of the results obtained with this adjuvant therapy in patients accrued over an 8-year period. Additionally, similar survival rates were observed regardless of the number of lymph nodes found to be positive for metastatic melanoma at the time of therapeutic lymph node dissection prior to initiation of adjuvant NDV oncolysate treatment. No survival advantage was observed in the small number of patients receiving NDV oncolysate made from both autologous and allogeneic melanoma cells; $50 \%$ of these four patients survived.

The current analysis of 15-year survival indicates that the protective effect on survival from this therapy that was observed at 10 years is continued in these patients (23). Because this phase II study was conducted with a small number of patients and did not include a control untreated patient group, caution must be exercised in drawing conclusions regarding the efficacy of this therapeutic approach (13). However, there appears to be substantial improvement in the survival of these NDV oncolysate-treated patients compared with the survival of patients with either therapeutic dissection of palpable nodes or elective lymph node dissection as reported in the literature. Patients with melanoma metastatic to regional lymph nodes (AJCC stage III) requiring therapeutic dissection of palpable lymph nodes have a historical 10-year survival rate of $6-15 \%(24-26)$. More recent studies of AJCC stage III patients have shown 10-year survival rates ranging from $33 \%$ to $41 \%(27,28,48)$ and a 15 -year survival rate of $38 \%(48)$. The improved survival in the latter studies appears to relate to the use of elective lymph node dissection, which provides for removal of early, nonpalpable lymph node disease, compared with the older studies in which therapeutic lymph node dissection was performed only for palpable lymph nodes. Overall, our current survival results and those obtained in the earlier phases of this study with NDV oncolysate have consistently shown a more favorable outcome than historical controls (18-23). Additionally, no other adjuvant studies to date have shown an equivalent or greater improvement in survival in this high-risk patient population (13). The longterm clinical benefit of this immunotherapeutic vaccine continues to suggest that treatment with NDV oncolysate may have played a role in keep- 
ing AJCC stage III malignant melanoma patients alive and free of detectable disease.

We have now begun to assess the immune repertoire in these treated patients in hopes of identifying parameters that may correlate with therapeutic efficacy. A number of previous studies have indicated that a local CD8 response to tumor may occur in melanoma patients and that these infiltrating $T$ cells represent expansions of a restricted set of TCR V $\beta$ gene families. However, as indicated by the generally poor prognosis, this response does not often result in effective tumor destruction. This could be due to the localized release of cytokines that are tumor suppressive, such as IL-10, at the site of the tumor (49). Alternatively, the presentation to $\mathrm{T}$ cells of tumor-derived peptides in the absence of co-stimulation may induce anergy and tolerance to the tumor itself. This is a potential hurdle on the road to successful immunotherapy (50).

Our results and those from other investigators suggest that chronic immunization may boost an effective anti-tumor response (51-53). Several investigators have studied the phenotype of $\mathrm{T}$ cells in melanoma patients. Elliott et al. conducted a comprehensive analysis of 139 patients with disseminated malignant melanoma who were enrolled in an uncontrolled phase II trial (52). This study evaluated the activity of an allogeneic tumor vaccine incorporating an adjuvant. The median survival time for patients treated with the vaccine was 23 months from diagnosis (43/139 censored patients). Precursor anti-melanoma TIL titers were increased in $42 \%$ of the patients who were evaluated. Interestingly, extended survival was observed among patients who displayed an expansion in the number of $\mathrm{CD} 8^{+} \mathrm{CD} 57^{+}$lymphocytes (34 months vs. 12 months) (52). In another study of 33 patients, a decrease in $\mathrm{CD} 57^{+}$cells was observed in patients with advanced or disseminated malignant melanoma (53). These observations point to a role for $\mathrm{CD} 8^{+} \mathrm{CD} 57^{+}$cells in an effective immune defense against these tumors.

Our findings clearly demonstrate an increased clonality within the CD8 $\mathrm{T}$ cell subset of NDV oncolysate-treated patients (see Fig. 3), with an overall increase in the percentage of $\mathrm{CD} 8^{+} \mathrm{CD} 57^{+} \mathrm{CD} 28^{-} \mathrm{T}$ cells in the peripheral blood. In addition, clonal expansions in this subset make up a large percentage of the total $\mathrm{CD} 8^{+}$ $\mathrm{T}$ cell population in treated melanoma patients, compared with normal controls (see Fig. 5). This subset of $T$ cells can be expanded in the setting of autoimmune diseases, bone marrow transplan- tation, and chronic viral infections and is also seen in some normal individuals, usually in an older age-groups (39). The control group in these studies was taken from the same age range as that of the melanoma subjects. These CD8 clonal expansions most likely represent terminally differentiated effector cells; this hypothesis is supported by our findings that these clonally expanded cells produce large amounts of TNF- $\alpha$ and IFN- $\gamma$ (Fig. 6) and function in cytotoxicity assays. We have observed in several individuals that these clonal expansions are present for years, a finding that suggests a response to a chronic and/or recurrent immune stimulus (37).

In tabulating these data we detected expansions of $\mathrm{T}$ cells expressing $\mathrm{V} \beta 8$ in the $\mathrm{CD} 8^{+} \mathrm{CD} 57^{+}$ subset in 7 out of 22 melanoma patients, while only 1 out of 30 controls had TCR V $\beta 8$ expansions (data not shown). However, it is currently unclear if this bias in the $\mathrm{V} \beta$ repertoire is significant; $\mathrm{a}$ thorough analysis would at minimum require controlling for the HLA background in these individuals as well as in normal age-matched controls. Several investigators have examined the TCR repertoire in tumor-infiltrating lymphocytes of malignant melanoma patients $(54,55)$. The results are conflicting, and no particular TCR V $\beta$ family has been reported to be consistently involved in the skewing of the $\mathrm{T}$ cell repertoire.

We have studied the TCR repertoire in one patient (patient 40 ) who recently had an axillary lymph node metastases, and compared the repertoire of $\mathrm{CD}^{+} \mathrm{T}$ cells from the lymph node and peripheral blood lymphocytes (PBL). Seven oligoclonal expansions were detected in the $\mathrm{CD}^{+} \mathrm{T}$ cells from PBMCs, while nine instances of clonality were detected in $\mathrm{CD}^{+} \mathrm{T}$ cells from lymph nodes. Two of these $\mathrm{V} \beta$ segments that were clonal in both sites were also expanded in the $\mathrm{CD} 8{ }^{+} \mathrm{CD} 57^{+}$subset of PBL. These observations suggest that the clonal expansions detected in peripheral blood are reflective of the ongoing immune response at the tumor site in at least some instances.

Viral oncolysates have been shown to induce remission, prolong life with reduced tumor burden, or decrease relapse rates for human cancers, although no significant effect on survival has yet been reported in large, randomized clinical trials using adjuvant viral oncolysates $(13,18,40,41)$. NDV has been used to induce tumor regression and its mode of action is postulated to occur, at least in part, through the cytolytic activity of $\mathrm{T}$ cells through their production of TNF- $\alpha$. Lorence et al. have reported that T73 and the wild-type isolate of NDV are potent inducers of TNF- $\alpha$ pro- 
duction by human PBMCs (43). In the current study it is unclear whether the presence of live NDV or the chronicity of the treatment is primarily responsible for the improved outcome in the patient population. To address this issue, studies are in progress in which chronic immunization of mice with the T73 oncolytic strain of NDV will be compared with the nonlytic Ulster strain in a melanoma model system. The overall sustained clinical benefit of NDV oncolysate as an adjuvant immunotherapeutic agent and the demonstrated involvement of $\mathrm{CD} 8 \mathrm{~T}$ cells in the ensuing immune response suggest that further investigation of the potential anti-tumor activity of CD8 T cells in these patients is warranted.

\section{Acknowledgments}

The authors thank Ms. Catherine Rapelje and Ms. Grace Lee for assistance with flow cytometric data acquisition, as well as Dr. Christina Sison and Mr. Robert Greenlee for assistance with biostatistical analysis.

\section{References}

1. Centers for Disease Control (1995) Deaths from melanoma-United States, 1973-1992. MMWR Morb. Mortal. Wkly. Rep. 44: 337, 343-347.

2. Rigel DS (1996) Malignant melanoma: perspectives on incidence and its effects on awareness, diagnosis, and treatment [editorial]. CA Cancer J Clin. 46: 195-198.

3. Ahmed I (1997) Malignant melanoma: prognostic indicators. Mayo Clin. Proc. 72: 356-361.

4. Day CL Jr, Mihm MC Jr, Lew RA, Kopf AW, Sober AJ, Fitzpatrick TB (1982) Cutaneous malignant melanoma: prognostic guidelines for physicians and patients. Cancer J. Clin. 32: 113-122.

5. Koh HK. (1991) Cutaneous melanoma. N. Engl. J. Med. 325: 171-182.

6. Demierre MF, Koh HK (1977) Adjuvant therapy for cutaneous malignant melanoma. J. Am. Acad. Dermatol. 6: 747-764.

7. Morton DL, Barth A (1996) Vaccine therapy for malignant melanoma. CA Cancer J. Clin. 45: 225-244.

8. Mukherji B, Chakraborty N (1995) Immunobiology and immunotherapy of melanoma. Curr. Opin. Oncol. 7: 175-184.

9. Ettinghousen SE, Rosenberg SA (1995) Immunotherapy and gene therapy of cancer. Adv. Surg. 28: 222-254.

10. Maio M (1996) Immunology of Human Melanoma: Tumor-Host Interaction and Immunotherapy. IOS Press, Amsterdam.

11. Barth A, Morton DL (1995) The role of adjuvant therapy in melanoma management. Cancer (Suppl.) 75: 726-734.
12. Reynolds SR, Oratz R, Sharpiro RL, et al. (1997) Stimulation of $\mathrm{CD}^{+} \mathrm{T}$ cell responses to MAGE-3 and Melan A/mart-1 by immunization to a polyvalent melanoma vaccine. Int. J. Cancer 72: 972-976.

13. Sondak VK, Wolfe JA (1997) Adjuvant therapy for melanoma. Curr. Opin. Oncol. 9: 189-204.

14. Livingston PO, Wong GYC, Adluri S, Tao Y, Padavan $M$, Parente R, et al. (1994) Improved survival in stage III melanoma patients with GM2 antibodies: a randomized trail of adjuvant vaccination with GM2 ganglioside. J. Clin. Oncol. 12: 1036-1044.

15. Barth A, Morton DL (1995) The role of adjuvant therapy in melanoma management. Cancer Suppl. 75: $726-734$.

16. Cohen J (1993) Cancer vaccines get a shot in the arm. Science 262: 841-843.

17. Kirkwood JM, Strawderman MH, Ernstoff MS, Smith TJ, Borden EC, Blum RH (1996) Interferon $\alpha-2 b$ adjuvant therapy of high-risk resected cutaneous melanoma: the Eastern Cooperative Oncology Group Trial EST 1684. J. Clin. Oncol. 14: 7-17.

18. Cassel WA (1986) Viruses in the cause and treatment of cancer. In: Grahm SD (ed). Urologic Oncology. Raven Press, New York, pp. 59-76.

19. Murray DR, Cassel WA, Torbin AH, Olkowski ZL, Moore ME (1977) Viral oncolysate in the management of malignant melanoma. II. Clinical studies. Cancer 40: 680-686.

20. Cassel WA, Murray DR (1986) Viral oncolysate in the treatment of regional metastases on melanoma. In: Larson DL, Ballantyne AJ, Guillamondegui OM (eds). Cancer in the Neck. Macmillan, New York, pp. 235-242.

21. Cassel WA, Weidenheim KM, Campbell WG, Murray DR (1986) Malignant melanoma: inflammatory mononuclear cell infiltrates in cerebral metastases during concurrent therapy with viral oncolysate. Cancer 57: 1302-1312.

22. Cassel WA, Murray DR (1988) Treatment of stage II malignant melanoma patients with a Newcastle disease virus oncolysate. Nat. Immun. Cell Growth Regul. 7: 351-352.

23. Cassel WA, Murray DR (1992) A ten-year follow-up on stage II malignant melanoma patients treated postsurgically with Newcastle disease virus oncolysate. Med. Oncol. Tumor Pharmocother. 9: 169-171.

24. Balch CM, Soong SJ, Murad TM, Ingalls AL, Maddox WA (1981) A multifactorial analysis of melanoma: III. Prognostic factors in melanoma patients with lymph node metastases (stage II). Ann. Surg. 193: 377-388.

25. Karakousis CP, Seddiq MK, Moore R (1980) Prognostic value of lymph node dissection in malignant melanoma. Arch. Surg. 115: 712-722.

26. Fortner JG, Woodruff J, Schottenfeld D, Maclean B (1977) Biostatistical basis of elective node dissection for malignant melanoma. Ann. Surg. 186: 101-103.

27. Bevilacqual RG, Coit DG, Rogatko A, Younes RN, Brennan MF (1990) Axillary dissection in mela- 
noma. Prognostic variables in node-positive patients. Ann. Surg. 212: 125-131.

28. Callery C, Cochran AJ, Roe DJ, et al. (1982) Factors prognostic for survival in patients with malignant melanoma spread to regional lymph nodes. Ann. Surg. 196: 69-75.

29. Murray DR, Cassel WA, Torbin AH, Olkowski ZL, Moore ME (1977) Viral oncolysate in the management of malignant melanoma. I. Preparation of the oncolysate and measurement of immunological responses. Cancer 40: 672-679.

30. Hingorani R, Choi I-H, Akolkar P, et al. (1993) Clonal predominance of $\mathrm{T}$ cell receptors within the $\mathrm{CD}^{+} \mathrm{CD}^{+} 5 \mathrm{RO}^{+}$subset in normal human subjects. J. Immunol. 151: 5762-5769.

31. Gregersen PK, Higorani R, Monteiro J (1994) Oligoclonality in the $\mathrm{CD} 8^{+} \mathrm{T}$ cell population: analysis using a multiplex PCR assay for CDR3 length. Proc. N.Y. Acad. Sci. 756: 19-27.

32. Callan MFC, Reyburn HTP, Bowness TH, et al. (1993) A method for producing monoclonal antibodies to human $\mathrm{T}$-cell receptor $\beta$-chain variable regions. Proc. Natl. Acad. Sci. U.S.A. 90: 10454-10458.

33. Choi Y, Kotzin BJ, Lafferty J, et al. (1991) A method for the production of antibodies to human T-cell receptor $\beta$-chain variable regions. Proc. Natl. Acad. Sci. U.S.A. 88: 8357-8361.

34. Friedman SM, Crow MK, Tumang JR, et al. (1991) Characterization of human T Cells reactive with the mycoplasma arthritis derived superantigen (MAM): generation of a monoclonal antibody against $V \beta$ 17, the $T$ cell receptor gene product expressed by a large fraction of MAM reactive human T cells. J. Exp. Med. 174: 891-900.

35. Padovan E, Casorati G, Drellabona P, Meyer S, Brockhaus M, and Lanzavechia A (1993) Expression of two $\mathrm{T}$ cell receptor alpha chains: dual receptor T cells. Science 262: 422-424.

36. Posnett DN, Romagne F, Necker A, Kotzin BL, Sekaly R-P (1996) First human TcR monoclonal antibody workshop. Immunologist 4: 5-9.

37. Morley JK, Batliwalla FM, Hingorani R, Gregersen PK (1995) Oligoclonal CD8 ${ }^{+} \mathrm{T}$ cells are preferentially expanded in the $\mathrm{CD} 57^{+}$subset. J. Immunol. 154: 6182-6190.

38. Monteiro J, Hingorani R, Choi I-H, Silver J, Pergolizzi R, Gregersen PK (1995) Oligoclonality in the human $\mathrm{CD}^{+} \mathrm{T}$ cell repertoire in normal subjects and monozygotic twins: implications for studies of infectious and autoimmune diseases. Mol. Med. 1: 614-624.

39. Batliwalla F, Monteiro J, Serrano D, and Gregersen PK (1996) Oligoclonality of $\mathrm{CD}^{+} \mathrm{T}$ cells in health and disease: aging, infection or immune regulation? Hum. Immunol. 48: 68-73.

40. Sinkovics J, Harvath J (1993) New developments in the virus therapy of cancer: a historical review. Intervirology 36: 193-214.

41. Sinkovics JG (1991) Viral oncolysate as human tumor vaccines. Int. Rev. Immunol. 7: 259-287.
42. Lorence RM, Reichard KW, Katubig BB, et al. (1994) Complete regression of human neuroblastoma xenografts in athymic mice after local Newcastle disease virus therapy. J. Natl. Cancer Inst. 86: 1228-1233.

43. Lorence RM, Rood PA, Kelley KW (1988) Newcastle disease virus as an antineoplastic agent: induction of tumor necrosis factor-alpha and augmentation of its cytotoxicity. J. Natl. Cancer Inst. 80: 1305-1312.

44. Cassel WA, Garrett RE (1965) Newcastle disease virus as an antineoplastic agent. Cancer 18: 863-868.

45. Liebrich W, Schlag P, Manasterski M, et al. (1991) In vitro and clinical characterization of Newcastle disease virus-modified autologous tumour cell vaccine for treatment of colorectal cancer patients. Eur. J. Cancer 27: 703-710.

46. Stoeck M, Marland-Noske C, Manasterski M, et al. (1993) In vitro expansion and analysis of $\mathrm{T}$ lymphocyte microcultures obtained form the vaccination sites of cancer patients undergoing active specific immunization with autologous Newcastle disease virus modified tumour cells. Cancer Immunol. Immunother. 37: 240-244.

47. Plaksin D, Porgador A, Vadai E, Feldman M, Schirrmacher V, Eisenbach L (1994) Effective anti-metastatic melanoma vaccination with tumor cells transfected with MHC genes and/or infected with Newcastle disease virus (NDV). Int. J. Cancer 59: 796-801.

48. Morton DL, Wanek L, Nisse JA, Elashoff RM, Wong JH (1991) Improved long-term survival after lymphadenectomy of melanoma metastatic to regional nodes. Ann. Surg. 214: 491-501.

49. Sato $P$, McCue $P$, Masuoka K (1996) Interleukin-10 production by human melanoma. Clin. Cancer Res. 21: 1383-1390.

50. Matzinger P (1994) Tolerance, danger, and the extended family. Annu. Rev. Immunol. 12: 991-1045.

51. Berd D, Maguire HC Jr, Schuchter LM, et al. (1997) Autologous hapten-modifed melanoma vaccine as postsurgical adjuvant treatment after resection of nodal metastases. J. Clin. Oncol. 15: 2359-2370.

52. Elliott GT, McLeod RA, Perez J, Von Eschen KB (1993) Interim results of a phase II multicenter clinical trial evaluating the acitivity of a therapeutic allogeneic melanoma vaccine (theraccine) in the treatment of disseminated malignant melanoma. Semin. Surg. Oncol. 9: 264-272.

53. Cartei G, Sala PG, Sanzari M, et al. (1993) Reduced lymphocyte subpopulations in patients with advanced or disseminated melanoma. J. Am. Acad. Dematol. 28: 738-744.

54. Nishimura M, Kawakami $Y$, Charmley $P$, et al. (1994) T-cell receptor repertoire in tumor-infiltrating lymphocytes. Analysis of melanoma-specific long-term lines. J. Immunother. 16: 85-94.

55. Sensi M, Farina C, Maccalli C, et al. (1997) Clonal expansion of $\mathrm{T}$ lymphocytes in human melanoma metastases after treatment with a hapten-modified autologous tumor vaccine. J. Clin. Invest. 99: 710-717. 